\title{
Functional Vegetable-Based Sausages for Consumption by Children
}

\author{
Solange Burri ${ }^{1,3}$, Isabel Tato ${ }^{2}$, Maria Leonor Nunes ${ }^{3}$, Rui Morais ${ }^{1 *}$ \\ ${ }^{1} \mathrm{CBQF} /$ Escola Superior de Biotecnologia-Universidade Católica Portuguesa, Rua Dr. António Bernardino de Almeida, Porto, \\ Portugal; ${ }^{2}$ QUALIMAR-Associação para o Desenvolvimento do Sector dos Produtos da Pesca e Agro Alimentar, Rua do Conde de \\ São Salvador, Matosinhos, Portugal; ${ }^{3}$ U-VPPA, Instituto Nacional de Recursos Biológicos, I.P./L-IPIMAR, Avenida de Brasília, \\ Lisboa, Portugal. \\ Email: ${ }^{*}$ rmmorais@esb.ucp.pt
}

Received February $9^{\text {th }}, 2011$; revised June $28^{\text {th }}, 2011$; accepted July $5^{\text {th }}, 2011$.

\begin{abstract}
The dislike food preferences that children registered regarding vegetables and fish compromise the exposure to those iodine sources and may contribute to cause a nutritional deficiency in this micronutrient, causing serious damage of the brain and the central nervous system. Functional foods are becoming well-established in the market, focused on by an adult consumer more interested in healthy eating habits but without the motivation to optimize natural food preparation or to promote a wide variety of food in his diet. This article presents evidence of a new functional product concept, $100 \%$ vegetable, fermented soya based and salted by red algae, that was approved by 900 parents who chose the sensorial features: distinctive aroma $(57.9 \%)$, soft texture (38.4\%), sausage shape (21\%) and attractive color $(77.9 \%)$. Three different varieties were developed: carrot $(50 \% \mathrm{w} / \mathrm{w})$, sugar-beet $(50 \% \mathrm{w} / \mathrm{w})$ and tomato $(40 \% \mathrm{w} / \mathrm{w})$ mini sausages, with tofu $(20 \% \mathrm{w} / \mathrm{w})$ and $0.8 \%(\mathrm{w} / \mathrm{w})$ of seaweed, reflecting trends that the younger consumer demands. The sensorial tests performed, after quality control assays, received very satisfactory acceptance by the potential buyer.
\end{abstract}

Keywords: Iodine, Children, Functional Product, Vegetable Sausages, Seaweed

\section{Introduction}

Obesity is an endemic problem in most developed countries, requiring serious public health attention because of the associated morbidity and mortality $[1,2]$. Overweight and obese people have a greater risk of developing cardiovascular risk factors such as hypercholesterolemia, hypertension and hyperlipidemia [3]. The importance of this health problem is also emphasized by the fact that prevalence rates tend to increase for children, adolescents and adults in most socioeconomic developed countries. The major causes associated with obesity impact revealed social issues such as urbanization, modernization of working practices and improvement of social conditions. These factors were exacerbated by sedentary lifestyles and bad nutritional habits [4], emphasized by the consumption of unhealthy food products, with poor nutritional value [5], that unfortunately also contribute to reduce the interest in healthy foods like fruits and vegetables, as pre-school children have recently demonstrated [6].

In Europe, several campaigns have been developed to promote and increase the consumption of vegetables, mainly by this social group. The advantages are considerable: 1) early intervention can lead to a maximum return of benefits in future health [7]; 2) implementation of healthy habits is more effective in this age group [8-9]. Consequently, it is important to offer parents attractive food options that can optimize the consumption of vegetables, frequently disliked, in children's food preferences. The exposure to healthy food, vegetable based, might also contribute to reduce the impact of diseases associated with like obesity, in developed countries. Some epidemiological studies showed that a high dietary intake of fruits and vegetables is strongly associated with the risk reduction of developing chronic diseases such cancer and cardiovascular diseases [10]. Therefore, this suggests that changes in dietary behavior, such as increasing consumption of vegetables together with a related healthier lifestyle could minimize the harmful impact of some diseases in future.

On the other hand, several studies have shown that some moderate single nutrient deficiencies may have a lasting impact on health risk of disease in adult life par- 
ticularly if they occur during critical periods of childhood development [11]. A decrease in actual amounts and types of foods eaten has resulted in a fall in micronutrients intakes, leaving the diet of significant numbers of children and adolescents bordering on the inadequate. This suggested that children and adolescents are the groups most likely to be at higher risk of nutritional deficiencies [12]. One example of this is the actual lack of iodine intake, revealed in a worldwide study in 1990; $28.9 \%$ of the population had iodine deficiency, $12 \%$ of the population exhibited goiter, 11.2 million people were affected by cretinism, and more than 43 million people had some degree of mental impairment due to insufficient iodine [13].

The physiological role for iodine in the human body lies in the synthesis of thyroid hormones by the thyroid gland and is implicated in major metabolic processes. Iodine deficiency affects all populations at all stages of life. However, children represent an important group where this micronutrient may cause serious damage of the brain and the central nervous system [14].

In Asia, seaweeds have been consumed as a vegetable since the beginning of time and represent an important dietary source of iodine. France is the only European country to establish a specific regulation concerning the use of seaweeds for human consumption as a non-traditional food ingredient [15] and may be incorporated into new food matrices. Gracilaria verrucosa authorized by this regulation seems to be often confused with Gracilaria vermiculophylla (Ohmi) [16] as studies in Portugal (Aveiro lagoon) recently reported [17]. This Rhodophyta, widely distributed in high salinity lagoons in Europe and USA East Coast [18-20], like most other seaweeds, has special nutritional characteristics and an interesting but minor level of iodine [21], that offers a higher degree of safety due to excessive intake of this micronutrient, and also can promote a more distinctive flavor, as revealed in western food preferences searches. Considering seaweeds have the capacity to bio-remove undesirable chemical compounds from aquatic systems [22], Gracilaria vermiculophylla, used in this study, was produced and controlled in an integrated phytotoculture system to ensure the continuous conditions required to monitor the levels of chemicals like $\mathrm{Pb}, \mathrm{Hg}, \mathrm{Cd}, \mathrm{Sn}$ and mineral As, and also iodine, as Agence Française de Securité Sanitaire des Aliments (AFSSA) recommends [23].

This article presents an overview of a pilot concept of a new functional product vegetable based with special features that children, in western countries, demand as consumers. Specially designed also to satisfy food intolerant consumers to some animal proteins, it is $100 \%$ vegetable.
The main goals of this article are: 1) to suggest the expansion of the industrial portfolio of processed food able to raise the dietary iodine intake, in children's diet; 2) to develop a novel process food product, vegetable and tofu based, that might contribute to the optimization of the consumption of vegetable proteins, obtained by organic production; 3) to promote the nutritional potential of seaweeds in European food habits exploring other alternative food resources and 4) to contribute to the reduction of unhealthy food consumption, especially by children.

\section{Experimental Section}

The development of a new functional vegetable-based sausage for consumption by children comprised two distinct steps:

a) a market study to gather data about Portuguese parents' expectations using a survey questionnaire disseminated in junior schools, on-line and personal interviews in supermarket areas. Participants were recruited only within Portugal. These data were collected, during 3 months, between February and April 2008, using a questionnaire that focused different aspects: 1) consumer profile, 2) vegetable eating frequency by children and 3) children's sensorial preferences for a new vegetable product. All statistical analysis was carried out using SPSS for Microsoft Windows (version 16.0).

b) the concept of an attractive product, with particular vegetable ingredients (vegetables, tofu, dried herb/spice and oil olive) and Gracilaria vermiculophylla, the seaweed collected from Aveiro lagoon/Portugal (40 49'31" $\mathrm{N} ; 08^{\circ} 39^{\prime} 58^{\prime \prime} \mathrm{W}$ ), dried at $45.0^{\circ} \mathrm{C} \pm 1^{\circ} \mathrm{C}$ for $48 \mathrm{~h}$ (Memmert, BM 600, Germany). After 26 preliminary assays, and regarding the major children's features chosen by parents, colored and creamy mini sausage models were developed based on several organic vegetables. The major steps on the experimental concept were:

1) Vegetables (carrot, sugar beet and tomato) washed and ground, cooked for 15 minutes after addition of olive oil, minced onion and tofu; 2) Dry herb/spice and seaweed were added in the last minutes of cooking; 3) Filling with vegetable casing and final thermal process in a steam oven (Rational Combimaster, CM 61, Germany) for 3 minutes at $100^{\circ} \mathrm{C}$.

c) the sensory evaluation of this new functional food took place with an adult and non-trained panel $(n=50)$, through a questionnaire focused on the features - taste, aroma, shape and texture-following French Norm NF XP V 09-500/2000 [36]. This test was performed with potential buyers without vegetarian habits, of both genders and with ages between 24 - 40 years. The criteria of assessment were based on the hedonic scale categories of 9 points [37,38]. The order of presentation of samples 
was swapped randomly and based on the method described by Cochran and Cox [39].

The results were grouped into classes by establishing ranges: $(1-3)$ : "extremely dislike - not like"; $(4-6)$ : "dislike slightly - like slightly" and (7 - 9): "like - like extremely".

\section{Results and Discussion}

\subsection{Market Study}

The inquiry made in Portugal, with a total of 900 responses $(n=900)$ by parents, distributed as follows: Table 1.

The use of a questionnaire in distinguished presentation formats has proved an effective strategy, fast and affordable, to gather a greater number of responses in order to understand parents expectations, regarding child preferences, towards the new vegetable product under study. Most of the responses were obtained via the internet $(62.8 \%)$, while personal interviews in supermarkets, represented only $23.9 \%$ of the total surveys sent. The responses from junior schools, frequented by children aged between 6 - 10 years, comprised only $13.3 \%$ of the total responses collected.

This sampling, enabled us to accumulate answers from different geographic locations, distinguished by temporal availability, jobs and interests, and contributed to obtain a more representative sample of the potential market, regarding the interest of potential consumers in the new product being developed, and covering all social levels.

\subsection{Survey Participant Profile}

The profile of consumers who agreed to cooperate in this study is shown in Table 2. The majority gender involved in this survey were women (86\%) compared with $14 \%$ males, which is consistent with the principal role of mothers in developing children's food habits, orientation and sensorial food preferences [24]. The majority of participants have a University degree (56\%), while $29 \%$ have a lower education and $15 \%$ of them have only basic school qualifications, the lower education level involved. This fact signifies that the majority of people involved in this analysis had a wide degree of information and could demonstrate more interest, knowing about functional food information, toward this new product, with additional nutritional value but expected high price.
Table 1. Distribution of surveys used in the study market.

\begin{tabular}{lcccc}
\hline & \multicolumn{4}{c}{ Surveys Distribution } \\
\cline { 2 - 5 } & Internet & $\begin{array}{c}\text { Personal } \\
\text { interview }\end{array}$ & Schools & Total \\
\hline Sent & 1200 & n.a. & 250 & 1450 \\
Obtained & 565 & 215 & 120 & 900 \\
Total & & & & \\
sent/received & $47.1 / 62.8$ & n.a. $/ 23.9$ & $48.0 / 13.3$ & 100.0 \\
$(\%)$ & & & & \\
\hline
\end{tabular}

Descendants of participants involved in the market analysis had, in the majority, ages below 3 years and above 15 years $(48 \%)$, where this iodine-enriched product should offer several and favorable impact: optimizing exposure to vegetables during their first years of life, where neophobic food resistance may compromise dietary intake [25], and iodine needs are higher, which will decrease with growth [14]. On the other hand, the generations above 15 years could be more food selective, with higher fast-food preferences, where a functional vegetable product could minimize unhealthy food consumption and help in food pathologies, if present.

The others age distributions appear to have very close results, with $12 \%$ and $15 \%$ for groups ( 3 - 5 years) and (11 - 15 years) respectively, while class (6 - 10 years) represented only $25 \%$ of responses. However, for all age, there seems to be a widespread parental concern about their children's diets and especially about consumption of vegetables, and therefore considerable motivation to develop new strategies to improve them [26].

\subsection{Children's Vegetables Consumption}

The reluctance to try new foods (food neophobic behavior) is common in children and studies have shown that the low consumption of fruits and vegetables have a negative impact on young children's learning [27]. According to some studies, factors influencing children's food acceptance seems to be: i) genetic reasons, ii) environmental reasons, iii) frequency with which these foods are offered and iv) strategies provided to encourage vegetable consumption, demonstrating the importance of parents and their target role in feeding behavior models [24,28]. An alternative perspective is focused on sensorial factors, e.g. reactions to taste, texture or appearance.

Some attempts to explain why vegetable consumption is so low, in children as well as adults, have often high-

Table 2. Profile of the participants involved in the study market.

\begin{tabular}{|c|c|c|c|c|}
\hline \multicolumn{5}{|c|}{ Study market parameters tested } \\
\hline Gender & $\mathbf{8 6} \%$ Female & $14 \%$ Male & & \\
\hline Age & $(20-30$ years) $16 \%$ & (31- 40 years) $\mathbf{6 0 \%}$ & (41- 50 years) $23 \%$ & (Other ages) 1\% \\
\hline Children ages & ( $3-5$ years) $12 \%$ & $(6-10$ years) $25 \%$ & $(11-15$ years) $\mathbf{1 5 \%}$ & (Other ages) $\mathbf{4 8 \%}$ \\
\hline
\end{tabular}


lighted taste preferences as a significant barrier [25,27].

A key determinant of children's food habits is familiarity, the means by which food becomes a direct experience, at home, and also by observing the feeding behavior of other family members [25]. The survey applied focused on some specific questions where parents should report the weekly frequency of consumption of vegetables by their sons. The results are shown in Figure 1.

All parents $(n=900)$ recognized the importance of introducing vegetables in their children's diets, knowing the favorable impact of these foods.

However, dealing with negative child food response, parents often witness difficulties in vegetable preferences and, after first refusals, some tend to discourage and give up offering vegetables, as may be observed in Figure 1. According to the results, the number of children that never eat vegetables seems to be higher when parents have more instruction, a fact that could evidence the performance of the social level of people with lower education level and, perhaps, with minor economic resources, that are not able to offer other kind of foods when children's neophobic response to vegetables begin. Curiously, the responses obtained for the other frequency rates were very close, for groups ( 1 - 5 times) and (6 - 10 times), for basic and high school, while the major education level registered an inferior value for (1 - 5 times) consumption (35\%) but registered $28 \%$ for (6 - 10 times) vegetables consumption. In all education levels, it seems common that children do not eat vegetables at all meals, since class ( $>15$ times) reported very low results. Some answers reported, "Don't know", appearing that vegetable consumption isn't controlled, or these participants don't have a direct role in children's food habits, perhaps indicated by fathers' participation in this survey ( $14 \%$ of total answers, Table 1).

\subsection{Major Sensorial Preferences}

Another issue in our market study was to understand what concept features of this product should be emphasized to attract younger consumer. The sensory preferences attracting more voted were: distinctive aroma

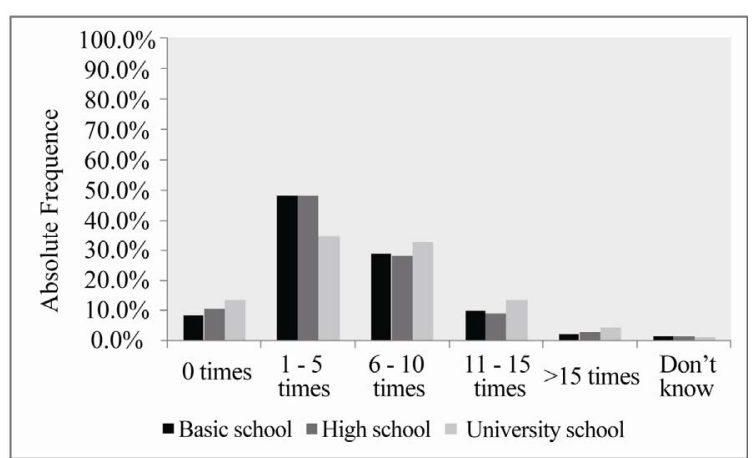

Figure 1. Children's consumption of vegetables versus education level of their parents.

(57.9\%), soft texture (38.4\%), sausage shape (21\%) and attractive color $(77.9 \%)$. Parents rapidly recognized the importance of stimulating a fast-food shape, easy hand eating, to convince children and, perhaps, decreasing other fast-food preferences. Attractive colors like red (14.2\%), orange $(13.6 \%)$ and green $(13.4 \%)$ seemed to be the best color features, at parents' eyes, that could stimulate younger consumption, representing a good opportunity to apply vegetable pigments in their natural matrix.

\subsection{Children's Vegetables Consumption}

After the development of a pilot assay $(n=26)$ the formulation of the sausages was found (Table 3).

AFSSA established major quality criteria that allow the food industry to include seaweeds as raw or semi- processed materials in the formulation of processed products [23]. All chemical levels monitored $(\mathrm{Cd}, \mathrm{Pb}, \mathrm{Hg}, \mathrm{Sn}$ and mineral As) were below the limits according to French regulations, as well iodide ion $\left(\mathrm{I}^{-}\right)$, the major source of iodine in seaweeds [29] and the only compound capable of being absorbed by thyroid gland [14].

It is essential in fostering new food products for children, to target their critical demands (e.g. iodine intake), but also to optimize industrial processes by using functional ingredients like tofu, herbs and/or seaweeds to offer processed food with enhanced nutritional value and

Table 3. Product formulation.

\begin{tabular}{|c|c|c|c|c|c|c|c|}
\hline & \multicolumn{7}{|c|}{ Sausages Formulation } \\
\hline & $\begin{array}{l}\text { Vegetable } \\
(\% \mathrm{w} / \mathrm{w})\end{array}$ & $\begin{array}{l}\text { Tofu } \\
(\% \mathrm{w} / \mathrm{w})\end{array}$ & Vegetable mix & $\begin{array}{l}\text { Olive oil }+ \text { onion } \\
(\% \mathrm{w} / \mathrm{w})\end{array}$ & Dry herb/spice & $\begin{array}{l}\text { Dry seaweed } \\
(\% \mathrm{w} / \mathrm{w})\end{array}$ & $\begin{array}{l}\text { Vegetal synthetic } \\
\text { casing }\end{array}$ \\
\hline Carrot sausage & $\begin{array}{l}\text { Carrot } \\
50.0\end{array}$ & 20.0 & added & 10.0 & $\begin{array}{l}\text { Whole nutmeg } \\
\text { (Myristica } \\
\text { fragans) }\end{array}$ & 0.8 & added \\
\hline $\begin{array}{l}\text { Sugar beet } \\
\text { sausage }\end{array}$ & $\begin{array}{l}\text { Sugar beet } \\
50.0\end{array}$ & 20.0 & added & 10.0 & $\begin{array}{l}\text { Rosemary } \\
\text { (Rosmarinus sp.) }\end{array}$ & 0.8 & added \\
\hline Tomato sausage & $\begin{array}{l}\text { Tomato } \\
40.0\end{array}$ & 20.0 & added & 10.0 & $\begin{array}{l}\text { Oregano } \\
\text { (Origanum vulgare) }\end{array}$ & 0.8 & added \\
\hline
\end{tabular}


that might also reduce sodium content.

The European Commission Concerted Action on Functional Food Science in Europe states that a food could have functional properties if it is satisfactorily demonstrated to affect beneficially one or more target functions in the body, besides adequate nutritional effects, in a way that is relevant to either an improved state of health or well-being and/or a reduction of risk of disease $[30,31]$. In this context, it is essential that the effects of functional foods should be confirmed in amounts that can normally be expected to be consumed in children's diet, such as iodine content, of which the optimal dietary intake should be $5.4 \mu \mathrm{g} / \mathrm{kg} /$ day for children aged between 1 - 10 years as Food and Nutrition Board of the United States National Academy of Sciences recommends [14]. This iodine amount was proposed to allow normal thyroid hormone production without stressing the thyroid mechanism, in all populations.

To achieve adequate micronutrient intakes, it is necessary to encourage children to make healthy food choices or to enrich their diets with the consumption of foods with a specific nutrient content, where their attitudes towards food should also be considered in order to stimulate the regular ingestion of this new product, that is essential to achieve the metabolic benefits expected [32].

Plant-based foods, like the sausages developed (Figure 2), with a high formulation of vegetables (40\% $50 \%$ ), soya with high digestibility and minor allergic potential like tofu $(20 \%)$, red seaweed $(0.8 \%)$ and with an aromatic herbs base, containing significant amounts of phytochemicals, may provide desirable health benefits beyond basic nutrition, reducing the risk of chronic diseases [30,31]. Particularly, phytochemicals like carotenoids with antioxidant effects (e.g. $\beta$-carotene present in carrot sausage and lycopene found in tomato sausage), phenolics (e.g. flavonoids like isoflavones found in tofu), alkaloids (e.g. present in herbs and spices), nitrogen-containing compounds (e.g. found in seaweeds) and organosulphur compounds present in most vegetable sources $[28,30]$, could offer enormous metabolic advantages in

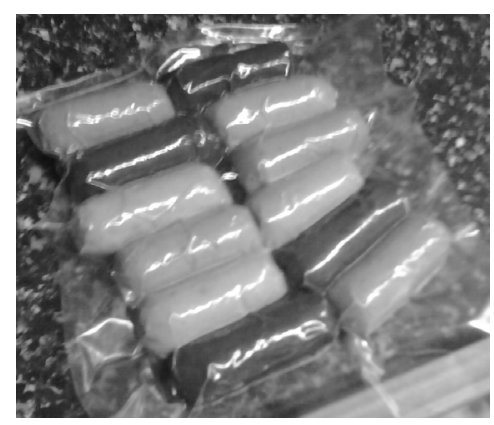

Figure 2. The product obtained, vegetable and fermented soya based sausages. an equilibrated diet despite the increase of iodine intake as the major functional effect required for children. Besides, the replacement of a product rich in vegetable protein could be very important, if protein complementarity is assured, to minimize saturated fat consumption and provide a more balanced diet. On the other hand, some studies have shown that soy products and its derivatives, rich in phytic acid, could inhibit the absorption of important minerals like calcium, iron and zinc and also increased the vitamin D needs [33], nutritional compounds very important in children's development. This product presents a particular functional formulation offering competitive value in the portfolio of the food industry. However, it is important not only to validate the bioavailability of each bioactive constituent present but also the effects of synergy and antagonism of their interactions within this new food matrix designed for children, regarding European Food Safety Agency (EFSA) Functional Food Regulation [32] and also Novel Foods rules.

It is also important to ensure, during industrial manufacture, the maintenance of biological activity of functional ingredients that will promote beneficial and functional effects, in this new product.

Technological processes should not compromise their value due to industrial processing and all steps should be mild to protect these beneficial properties without compromising quality control or sensorial characteristics [34].

The result of this work, vegetable-based mini sausages with tofu, G. vermiculophylla and herbs, can be consumed not only by children, but also by pregnant women, individuals with bovine protein allergies, vegetarians or vegans and population groups whose ethnicity denies some kind of meat consumption. Furthermore, the therapeutic potential that this product may offer, as an iodine supply, could be very interesting in oncological patients with hormonal imbalances.

Microbiological quality control of the final product was analysed by total count $\left(30^{\circ} \mathrm{C}\right)$ and moulds count $\left(22^{\circ} \mathrm{C}\right)$, Clostridium spp., Listeria monocytogenes, Salmonella spp., Bacillus cereus and faecal coliforms following standard ISO issues for these quality criteria.

All results were below the limits recommended by the UK Public Health Laboratory Service (PHLS) guidelines for vegetables, ready to eat, products [35].

\subsection{Sensorial Assay}

The results obtained regarding the sensorial test, of the three types of sausages designed - carrot, sugar beet and tomato are in Figure 3.

Based on the results obtained it appears that the individual analysis, without cross comparisons, made of the three sausages developed, showed very satisfactory re- 

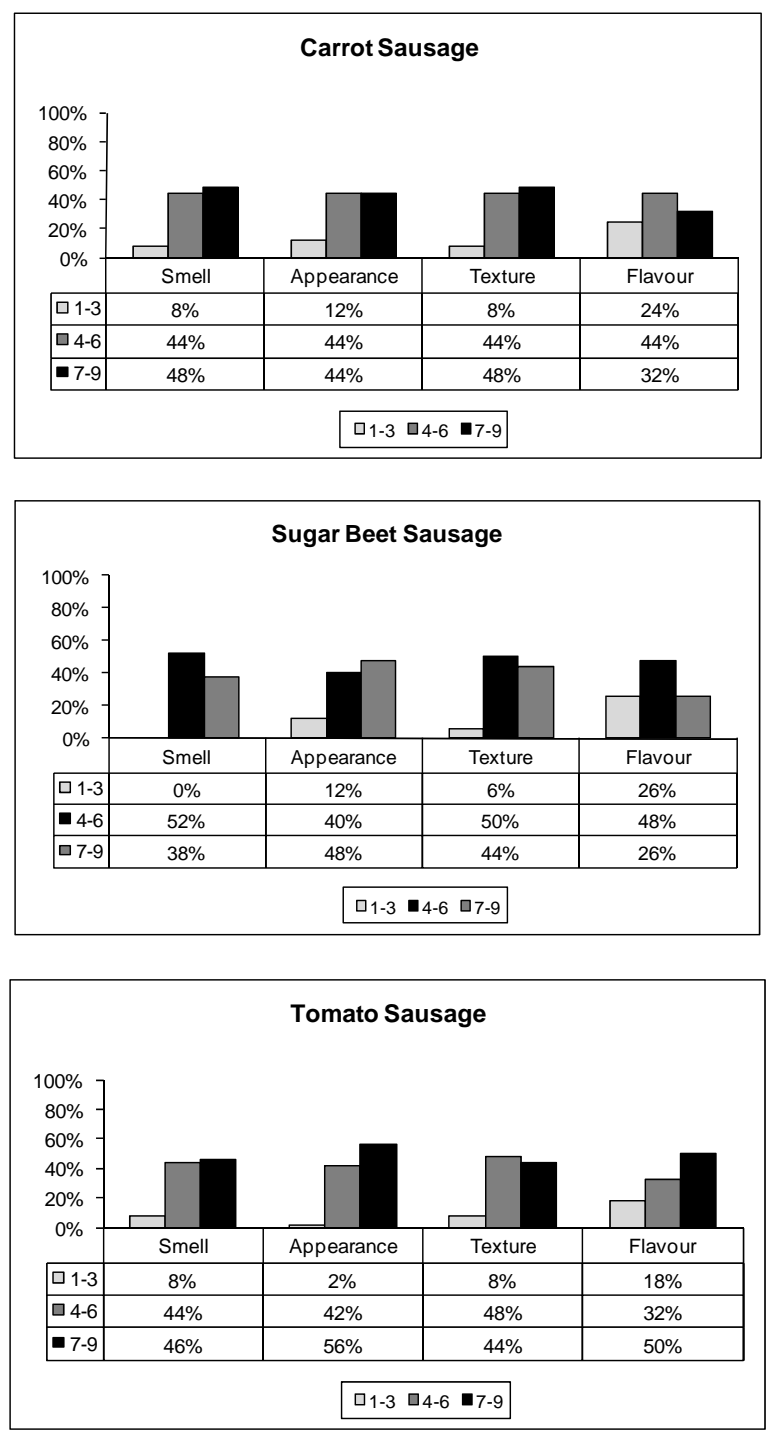

Figure 3. Absolute frequencies of sensory evaluation of varieties of product developed: (1 - 3): "extremely dislike - not like”, (4 - 6): “dislike slightly - like slightly”, (7 - 9): “like like extremely”.

sults for the criteria applied: aroma, appearance, texture and flavour.

Analysing the criteria under observations, there seems to be a clear preference for carrot and tomato sausages and less favourable for sugar beet sausage, which is consistent with the particular flavour that this vegetable has and not always sought after. Thus, the tomato sausage received the highest preference of the consumer panel with respect to the parameters appearance $((7-9)-56 \%)$ and flavour $((7-9)-50 \%)$ while the carrot sausage was highlighted in the evaluation of the aroma and texture with $((7-9)-48 \%)$ for both this criteria.

However, in the middle class (4 - 6)—dislike slightly like slightly, beet sugar sausage has also demonstrated satisfactory results in the parameters of aroma $(52 \%)$, texture $(50 \%)$ and flavour $(48 \%)$ but the appearance, with typical purple colour, seems less appealing for the panel envolved (40\%).

\section{Conclusions}

There is a consensus that the nutrients obtained from a diet high in fruit and vegetables can contribute to the prevention of cancer and cardiovascular disease and, in addition, may displace other foods from the diet, thereby indirectly reduce animal protein and saturated fat consumption [30,31].

Despite the regular rejection of vegetables, children need to be often exposed to this kind of food, preferring always the natural presentation of vegetables, with higher nutritional value. Alternatively, parents could increase vegetable exposure with processed food, like new design foods, as functional products. On the other hand, it seems essential to foster new food products for children, targeting their critical demands and optimize, at home, the availability of appealing alternatives that might decrease the consumption of unhealthy food and contribute, in future, to reducing the impact of food pathologies like obesity or diabetes. So, it is important to promote comprehensive information to parents about the ideal application of functional foods, otherwise their value might be underestimated, necessary to assure maximum healthy effect. Public health intervention, targeted to specific population groups, with low socioeconomic level or low-education level groups, where higher levels of obesity are found [4] should also stimulate an attractive diet, focusing also on these potential products where a regular intake can contribute to minimize nutritional deficiencies.

There are a number of limitations to the present study which could be usefully addressed in future research. In common with many published studies about nutritional deficiencies, especially in children, it is important to understand which social, psychological and economic factors should be the focus of health professionals to re-educate family food habits and what food education exists, at home. Furthermore, iodine intake could be increased with a regular exposure to vegetable and fish consumption but children's high demands for this essential element couldn't be satisfied if parent's didn't overcome neophobic responses that this kind of food induces.

A new and modern life style demands more interest, by the consumer, in processed foods. Food designers should increase their efforts to optimize different technological processes to assure a higher nutritional value for food products as well as the application of ingredients with superior value, like seaweeds represent. The development of new industrial strategies to reduce, and replace, 
seaweeds as sodium source, should offer good perspectives to overcome iodine deficiency. Thereby, programmes of salt iodization might be replaced by this potential food resource, with a secular history in Asiatic countries. Iodine should be quantified per meal after processing, and during the shelf life of the product and could be comparatively small, with the daily intake level expected, with regard to the distinct flavor expected for this product, and adequate salt level and a child's portion ingested.

On the other hand, and despite satisfactory sensorial results obtained, new organoleptic tests should be undertaken with child consumers, to adjust this product to their preferences, after the last industrial optimization and finally quality control, focusing on the strict limits required for special foods.

One of the most important longer-term contributions of this line of research may be to improve the advice given to parents on how to manage functional food consumption, particularly in children, and how to minimize nutritional deficiencies in this susceptible group. Nutritional education must be prioritized and target nutritionally vulnerable groups like children, considering that food enrichment, with or without functional character, should never replace a balanced healthy diet.

\section{Acknowledgements}

We would like to express our greatest thanks to the professional team of CIIMAR/CIMAR - Oporto/Portugal for offering Gracilaria vermiculophylla samples used in this study and by its technical control. Rui Morais acknowledges financial support from programme Plurianual of Fundação para a Ciência e Tecnologia (FCT) of Portuguese Republic Government.

\section{REFERENCES}

[1] World Health Organization, "Obesity: Preventing and Managing the Global Epidemic," Report of a WHO Consultation on Obesity, World Health Organization, Geneva, 1997.

[2] World Health Organization, "Obesity: Preventing and Managing the Global Epidemic," Report of a WHO Consultation on Obesity, WHO Technical Report Series 894, Geneva, 2000.

[3] A. Pietrobelli, S. Rugolotto, P. de Cristofaro and M. Malavolti, "Pediatric Obesity: Looking into Treatment," Nutrients, Vol. 1, No. 2, 2009, pp. 197-209. doi:10.3390/nu1020197

[4] I. do Carmo, O. dos Santos, J. Camolas, J. Vieira, M. Carreira, L. Medina, L. Reis, J. Myatt and A. GalvãoTeles, "Overweight and Obesity in Portugal: National Prevalence in 2003-2005," Obesity Reviews, Vol. 9, No. 1, 2007, pp. 11-19.

doi: $10.1111 / \mathrm{j} .1467-789 X .2007 .00422 . \mathrm{x}$
[5] S. W. Keith, D. T. Redden, P. T. Katzmarzyk, M. M. Boggiano, E. C. Hanlon, R. M. Benca, D. Ruden, A. Pietrobelli, J. L. Barger, K. R. Fontainer, C. Wang, L. J. Aronne, S. M. Wright, M. Baskin, N. V. Dhurandhar, M. C. Lijoi, C. M. Grilo, M. DeLuca, A. O. Westfall and D. B. Allison, "Putative Contributors to the Secular Increase in Obesity: Exploring the Roads Less Traveled," International Journal of Obesity, Vol. 30, 2006, pp. 1585-1594. doi:10.1038/sj.ijo.0803326

[6] L. J. Cooke, J. Wardle, E. L. Gibson, M. Sapochnik, A. Sheiham and M. Lawson, "Demographic, Familial and Trait Predictors of Fruit and Vegetable Consumption by Preschool Children," Public Health Nutrition, Vol. 7, No. 2, 2004, pp. 295-302. doi:10.1079/PHN2003527

[7] C. L. Perry, D. B. Bishop, G. Taylor, D. M. Murray, R. W. Mays, B. S. Dudovitz, M. Smyth and M. Story, "Changing Fruit and Vegetable Consumption among Children: The 5-a-Day Power Plus Program in St Paul, Minnesota," American Journal of Public Health, Vol. 88, No. 4, 1998, pp. 603-609. doi:10.2105/AJPH.88.4.603

[8] K. Resnicow, M. Smith, T. Baranowski, J. Baranowski, R. Vaughan and M. Davis, "2-Year Tracking of Children's Fruit and Vegetable Intake," Journal of American Dietetic Association, Vol. 98, No. 7, 1998, pp. 785-789. doi:10.1016/S0002-8223(98)00177-1

[9] M. R. Singer, L. L. Moore, E. J. Garrahie and R. C. Ellison, "The Tracking of Nutrient Intake in Young Children: The Framingham Children's Study," American Journal of Public Health, Vol. 82, No. 12, 1995, pp. 1673-1677. doi:10.2105/AJPH.85.12.1673

[10] R. H. Liu, "Health Benefits of Fruits and Vegetables are from Additive and Synergistic Combination of Phytochemicals," American Journal of Clinical Nutrition, Vol. 78, No. 3, 2003, pp. 517S-520S.

[11] European Society for Paediatric Gastroenterology, Hepatology and Nutrition (ESPGHAN), "Complementary Feeding: A Commentary by the ESPGHAN Committee on Nutrition," Journal of Pediatric Gastroenterology and Nutrition, Vol. 46, No. 1, 2008, pp. 99-100. doi:10.1097/01.mpg.0000304464.60788.bd

[12] J. Westenhoefer, "Establishing Good Dietary HabitsCapturing the Minds of Children," Public Health Nutrition, Vol. 4, No. 1A, 2001, pp. 125-130. doi:10.1079/PHN2000107

[13] WHO, UNICEF and ICCIDD, "Indicators for Assessing Iodine Deficiency Disorders and their Control through Salt Iodization," World Health Organization, Geneva, 1994.

[14] F. Delange, "Iodine Requirements during Pregnancy, Lactation and the Neonatal Period and Indicators of Optimal Iodine Nutrition," Public Health Nutrition, Vol. 10, No. 12A, 2007, pp. 1571-1580. doi:10.1017/S1368980007360941

[15] P. Burtin, "Nutritional Value of Seaweeds," Electronic Journal of Environmental, Agricultural and Food Chemistry, Vol. 2, No. 4, 2003, pp. 498-503.

[16] G. Papenfuss, "Notes on Algal Nomenclature-Various Chlorophyceae and Rhodophyceae," Phykos, Vol. 5, No. 
1-2, 1967, pp. 95-105.

[17] G. W. Saunders, "Routine DNA Barcoding of Canadian Gracilariales (Rhodophyta) Reveals the Invasive Species Gracilaria vermiculophylla in British Columbia," Molecular Ecology Resources, Vol. 9, No. S1, 2009, pp. 140-150. doi:10.1111/j.1755-0998.2009.02639.x

[18] M. Thomsen, P. Staehr, C. Nyberg, S. Schwaerter, D. Krause-Jensen and B. Silliman, "Gracilaria vermiculophylla (Ohmi) Papenfuss, 1967 (Rhodophyta, Gracilariaceae) in Northern Europe, with Emphasis on Danish Conditions, and What to Expect in the Future," Aquatic Invasion, Vol. 2, No. 2, 2007, pp. 83-94. doi:10.3391/ai.2007.2.2.1

[19] J. Rueness, "Life History and Molecular Sequences of Gracilaria vermiculophylla (Gracilariales, Rhodophyta): a New Introduction to European Waters," Phycologia, Vol. 44, No. 1, 2005, pp. 120-128. doi:10.2216/0031-8884(2005)44[120:LHAMSO]2.0.CO;2

[20] A. M. Bellorin, M. C. Oliveira and E. C. Oliveira, "Gracilaria vermiculophylla: A Western Pacific Species of Gracilariaceae (Rhodophyta) First Recorded from Eastern Pacific," Phycological Research, Vol. 52, No. 2, 2004, pp. 69-79. doi:10.1111/j.1440-1835.2004.tb00317.x

[21] X. Hou and X. Yan, "Study of the Concentration and Seasonal Variation of Inorganic Elements in 35 Species of Marine Algae," The Science of Total Environment, Vol. 222, No. 3, 1998, pp. 141-156. doi:10.1016/S0048-9697(98)00299-X

[22] M. Munilla, I. Gomez-Pinilla, S. Ródenas and M. Larrea, "Determination of Metals in Seaweeds Used as Food by Inductively Coupled Plasma Atomic-Emission Spectrometry," Analysis, Vol. 23, No. 9, 1995, pp. 463-466.

[23] Réglementation Algues Alimentaires MAJ 2010, Synthése CEVA Avril, 2010. http://www.ceva.fr/fre/S-INFORMER/SCIENCES-TECN IQUES/Algues-Alimentaires/Reglementation-FrancaiseAlgues-alimentaires/Synthese-Ceva-avril-2010

[24] E. Cashdan, "Adaptiveness of Food Learning and Food Aversions in Children," Social Science Information, Vol. 37, No. 4, 1998, pp. 613-632. doi: $10.1177 / 053901898037004003$

[25] E. L. Gibson, J. Wardle and C. J. Watts, "Fruit and Vegetable Consumption, Nutritional Knowledge and Beliefs in Mothers and Children," Appetite, Vol. 31, No. 2, 1998, pp. 205-228. doi:10.1006/appe.1998.0180

[26] L. Cooke, J. Wardle and E. Gibson, "The Relationship between Child Food Neophobia and Everyday Food Consumption," Appetite, Vol. 41, No. 2, 2003, pp. 95-96. doi:10.1016/S0195-6663(03)00048-5

[27] J. D. Skinner, B. R. Carruth, W. Bounds and P. J. Ziegler,
"Children's Food Preferences: A Longitudinal Analysis," Journal of American Dietetic Association, Vol. 102, No. 11, 2002, pp. 1638-1647. doi:10.1016/S0002-8223(02)90349-4

[28] A. Drewnowski, and C. Gomez-Carneros, "Bitter Taste, Phytonutrients and the Consumer: A Review," American Journal of Clinical Nutrition, Vol. 72, No. 6, 2000, pp. 1424-1435.

[29] X. L. Hou, C. F. Chai, Q. F. Qian, X. J. Yan and X. Fan, "Determination of Chemical Species of Iodine in Some Seaweed's (I)," The Science of the Total Environment, Vol. 204, No. 3, 1997, pp. 215-221. doi:10.1016/S0048-9697(97)00182-4

[30] R. Liu, "Potencial Synergy of Phytochemicals in Cancer Prevention: Mechanism of Action," The Journal of Nutrition, Vol. 134, No. 12, 2004, pp. 3479S-3484S.

[31] World Cancer Research Fund, "Food Nutrition and the Prevention of Cancer: A Global Perspective," American Institute for Cancer Research, Washington, 1995, pp. 1315.

[32] European Commission Concerted Action on Functional Food Science in Europe, "Scientific Concepts of Functional Foods in Europe", British Journal of Nutrition, Vol. 81, No. S1, 1999, pp. S1-S27.

[33] K. Montgomery, "Soya Protein: Nutrition Column," The Journal of Perinatal Education, Vol. 12, No. 3, 2003, pp. 42-45.

[34] R. Morais, "Functional Foods-An Introductory Course," Greca Artes Gráficas-Escola Superior de Biotecnologia/UCP, Porto, 2001.

[35] PHLS Working Group (R. J. Gilbert, J. de Louvois, T. Donovan, C. Little, K. Nye, C. D. Ribeiro, J. Richards, D. Roberts and F. J. Bolton), "Guidelines for the Microbiological Quality of Some Ready-to-Eat Foods Sampled at the Point of Sale of the PHLS Advisory Committee for Food and Dairy Products," Commun Disease Public Health, Vol. 3, No. 3, 2000, pp. 163-167.

[36] Normalisation Française XP V 09-500, “Analyse sensorielle. Directives Genérales Pour la Réalization d'épreuves Hédoniques en Laboratoire d'évaluation Sensorielle ou en salle en Conditions Contrôlées Impliquant dês Consommateurs," AFNOR, France, 2000.

[37] D. Peryam, N. Girardot, "Advanced Taste-Test Method," Food Engineering, Vol. 24, No. 7, 1952, pp. 58-61.

[38] D. Peryam, F. Pilgrim, "Hedonic Scale Method of Measuring Food Preferences," Food Technology, Vol. 11, No. S1, 1957, pp. 9-14.

[39] W. G. Cochran and G. M. Cox, "Experimental Design," John Wiley \& Sons, New York, 1957. 